\title{
Secukinumab is Superior to Ustekinumab in Clearing Skin in Patients with Moderate to Severe Plaque Psoriasis (16-Week CLARITY Results)
}

\author{
Jerry Bagel · John Nia · Peter W. Hashim • Manmath Patekar • \\ Ana de Vera · Sophie Hugot · Kuan Sheng · Summer Xia • \\ Isabelle Gilloteau • Elisa Muscianisi · Andrew Blauvelt • \\ Mark Lebwohl
}

Received: August 28, 2018 / Published online: October 17, 2018

(C) The Author(s) 2018

\section{ABSTRACT}

Introduction: Secukinumab, a fully human antiinterleukin-17A monoclonal antibody, has

Enhanced digital features To view enhanced digital features for this article go to https://doi.org/10.6084/ m9.figshare.7140818.

Electronic supplementary material The online version of this article (https://doi.org/10.1007/s13555018-0265-y) contains supplementary material, which is available to authorized users.

J. Bagel ( $\square)$

Psoriasis Treatment Center of Central New Jersey,

East Windsor, NJ, USA

e-mail: dreamacres1@aol.com

J. Nia · P. W. Hashim · M. Lebwohl

Icahn School of Medicine at Mount Sinai, New York, NY, USA

M. Patekar · A. de Vera · S. Hugot · I. Gilloteau Novartis Pharma AG, Basel, Switzerland

K. Sheng · E. Muscianisi

Novartis Pharmaceuticals Corporation, East

Hanover, NJ, USA

S. Xia

Novartis Beijing Novartis Pharma Co. Ltd, Shanghai, China

A. Blauvelt

Oregon Medical Research Center, Portland, OR, USA demonstrated superior efficacy to ustekinumab in the phase 3b CLEAR study of moderate to severe plaque psoriasis. Here, we report 16-week results from CLARITY, a second head-to-head trial comparing secukinumab with ustekinumab. Methods: In the phase 3b CLARITY study, patients were randomized $1: 1$ to receive subcutaneous secukinumab $300 \mathrm{mg}$ or ustekinumab per label. The co-primary objectives were to demonstrate the superiority of secukinumab over ustekinumab at Week 12 in relation to the proportion of patients with (1) $90 \%$ or more improvement from baseline Psoriasis Area and Severity Index (PASI 90) and (2) a score of $0 / 1$ (clear/almost clear) on the modified Investigator's Global Assessment (IGA mod 2011 0/1). Key secondary objectives were also assessed, as was Dermatology Life Quality Index (DLQI) 0/1 (no impact of skin disease on patients' quality of life) response. Missing values were handled by multiple imputation except for DLQI 0/1, where last observation carried forward techniques were utilized.

Results: Both co-primary objectives were met: secukinumab was superior to ustekinumab for the proportion of patients achieving a PASI 90 (66.5\% vs. $47.9 \%)$ and IGA $\bmod 20110 / 1$ response $(72.3 \%$ vs. $55.4 \%)$ at Week 12 $(p<0.0001)$. PASI 90 responses were greater with secukinumab compared to ustekinumab from as early as Week 4 (16.7\% vs. $4.0 \%)$ and out to Week 16 (76.6\% vs. 54.2\%). Similarly, IGA mod 2011 0/1 findings were greater with 
secukinumab at Week $4(26.9 \%$ vs. $7.8 \%)$ and at Week 16 (78.6\% vs. 59.1\%). DLQI 0/1 response rates were also greater with secukinumab compared to ustekinumab at Week $4(33.9 \%$ vs. $18.0 \%)$, Week 12 (64.0\% vs. 51.7\%), and Week 16 (68.4\% vs. $55.9 \%)$.

Conclusion: The results of this study confirm the superior efficacy of secukinumab over ustekinumab in treating patients with moderate to severe psoriasis.

Trial Registration: Clinicaltrials.gov Identifier, NCT02826603.

Funding: Novartis Pharma AG, Basel, Switzerland.

Keywords: Moderate to severe psoriasis; Secukinumab; Ustekinumab

\section{INTRODUCTION}

Treatment approaches in psoriasis range from traditional topical therapy and phototherapy to systemic interventions that target the immune system at different stages. Systemic therapies have advanced over time to target psoriasisspecific immune cytokines such as interleukin (IL)-12/23, or recently IL-17A, and their associated signaling pathways. Ustekinumab (an IL$12 / 23$ inhibitor) has demonstrated good clinical efficacy in phase 3 studies with better Psoriasis Area Severity Index (PASI) response rates than those of etanercept (a tumor necrosis factor [TNF] inhibitor) $[1,2]$.

Secukinumab is a fully human monoclonal antibody that selectively neutralizes IL-17A, a key effector cytokine involved in the development of psoriasis $[3,4]$. In the 52 -week doubleblinded CLEAR study, secukinumab (79.0\%) was found to be superior to ustekinumab $(57.6 \%)$ as assessed by PASI 90 response at Week $16(p<0.0001)[5]$ and Week $52(p<0.0001)$ [6]. Superior clinical efficacy with secukinumab was also associated with significantly greater improvement in health-related quality of life (HRQoL) when compared with ustekinumab. In the current study, we report 16-week results from the 52-week CLARITY study, the second head-to-head trial comparing secukinumab with ustekinumab in moderate to severe plaque psoriasis. Distinct from the CLEAR study, CLARITY includes a larger patient population $(N=1102$ vs. $N=676)$, a greater proportion of US patients $(64.2 \%$ vs. $12.6 \%)$, and an assessment of primary efficacy objectives at Week 12 (vs. Week 16).

\section{METHODS}

\section{Study Population}

Patients ( $\geq 18$ years) with moderate to severe chronic plaque psoriasis (PASI $\geq 12$, static 5-point Investigator's Global Assessment 2011 modified version [IGA mod 2011] score $\geq 3$, and body surface area [BSA] involvement $\geq 10 \%$ ) and who were inadequately controlled by topical treatments, phototherapy, and/or previous systemic therapy were eligible (key exclusion criteria are presented in Table S1).

\section{Study Design}

CLARITY (NCT02826603) is a multicenter, randomized, double-blinded, active-controlled, parallel-group, phase $3 \mathrm{~b}$ trial. Eligible patients were randomized 1:1 to receive either subcutaneous secukinumab $300 \mathrm{mg}$ at Baseline, Weeks 1,2 , and 3 , and then every 4 weeks from Weeks 4 to 48 , or subcutaneous ustekinumab $(45 \mathrm{mg}$ for patient weighing $\leq 100 \mathrm{~kg}$ or $90 \mathrm{mg}$ for patient weighing $>100 \mathrm{~kg}$ ) at Baseline, Week 4, and then every 12 weeks (Fig. 1).

\section{Study Objectives}

The co-primary objectives of the study were to demonstrate the superiority of secukinumab compared to ustekinumab with respect to PASI 90 response and IGA mod 2011 0/1 (clear or almost clear skin) at Week 12 . The following key secondary objectives were assessed sequentially by a hierarchical testing strategy, which tested the superiority of secukinumab compared to ustekinumab with respect to (in hierarchical order): PASI 75 response at Week 12, PASI 75 response at Week 4, PASI 90 at Week 16, PASI 


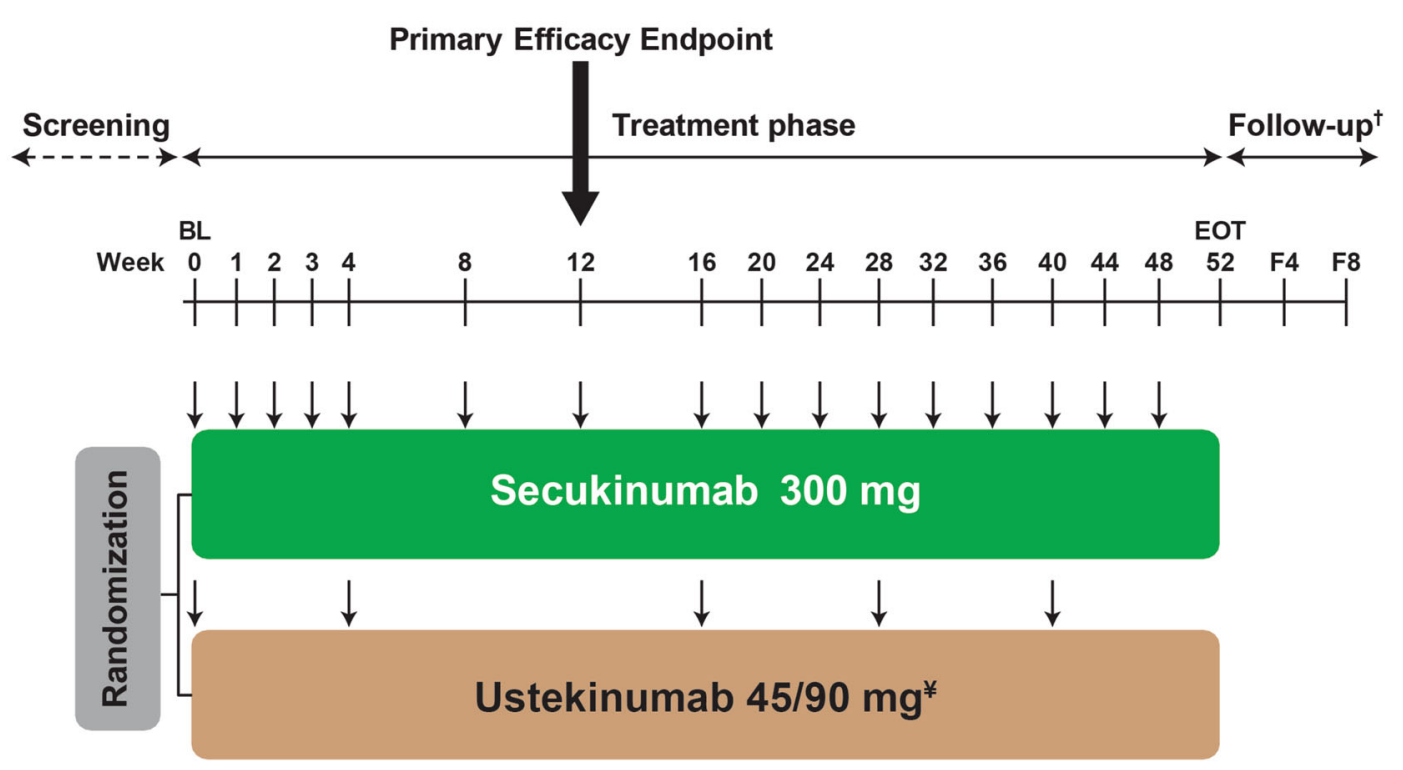

Fig. 1 Study design of the CLARITY study. ${ }^{\text {”}}$ Ustekinumab dose is based on body weight at baseline; $45 \mathrm{mg}$ for patient $\leq 100 \mathrm{~kg} ; 90 \mathrm{mg}$ for patient $>100 \mathrm{~kg}$. ${ }^{\dagger}$ For patients with premature treatment discontinuation only. $\mathrm{F} 4=$ follow-up visit approximately 4 weeks after the EOT visit. F8 $=$ follow-up visit approximately 8 weeks after the

100 at Week 16, IGA mod 2011 0/1 at Week 16, PASI 100 at Week 12, and PASI 75 at Week 16. Dermatology Life Quality Index (DLQI) 0/1 response (representing no impact of skin disease on patients' quality of life) was also assessed at Weeks 4, 12, and 16.

\section{Statistical Analyses}

Co-primary variables and key secondary variables were evaluated using a logistic regression model with treatment group, baseline body weight strata ( $\leq 100 \mathrm{~kg},>100 \mathrm{~kg}$ ), and baseline PASI as explanatory variables. Missing values were handled by multiple imputation except for DLQI 0/1, where missing values were handled using last observation carried forward.

\section{Study Oversight}

All procedures performed in studies involving human participants were in accordance with the ethical standards of the institutional and/or national research committee and with the 1964
EOT visit. $\downarrow=$ active dose administration; in order to maintain blinding, patients received placebo administrations at several time points (not shown in this study design figure). The screening phase duration was at least 2 weeks and up to 4 weeks. $B L$ baseline, EOT end of treatment phase

Helsinki declaration and its later amendments or comparable ethical standards. Informed consent was obtained from all individual participants included in the study.

\section{RESULTS}

\section{Study Population}

A total of 1102 patients, of whom almost twothirds were US patients $(64.2 \%)$, were randomized to either secukinumab $300 \mathrm{mg}(n=550)$ or ustekinumab $45 / 90 \mathrm{mg}(n=552)$. The rate of discontinuation was low and balanced between treatment arms (Fig. 2). Similarly, demographic and baseline disease characteristics were well balanced across patients (Table 1).

\section{Efficacy}

Both co-primary objectives were met: secukinumab was superior to ustekinumab for the proportion of patients that achieved PASI 90 


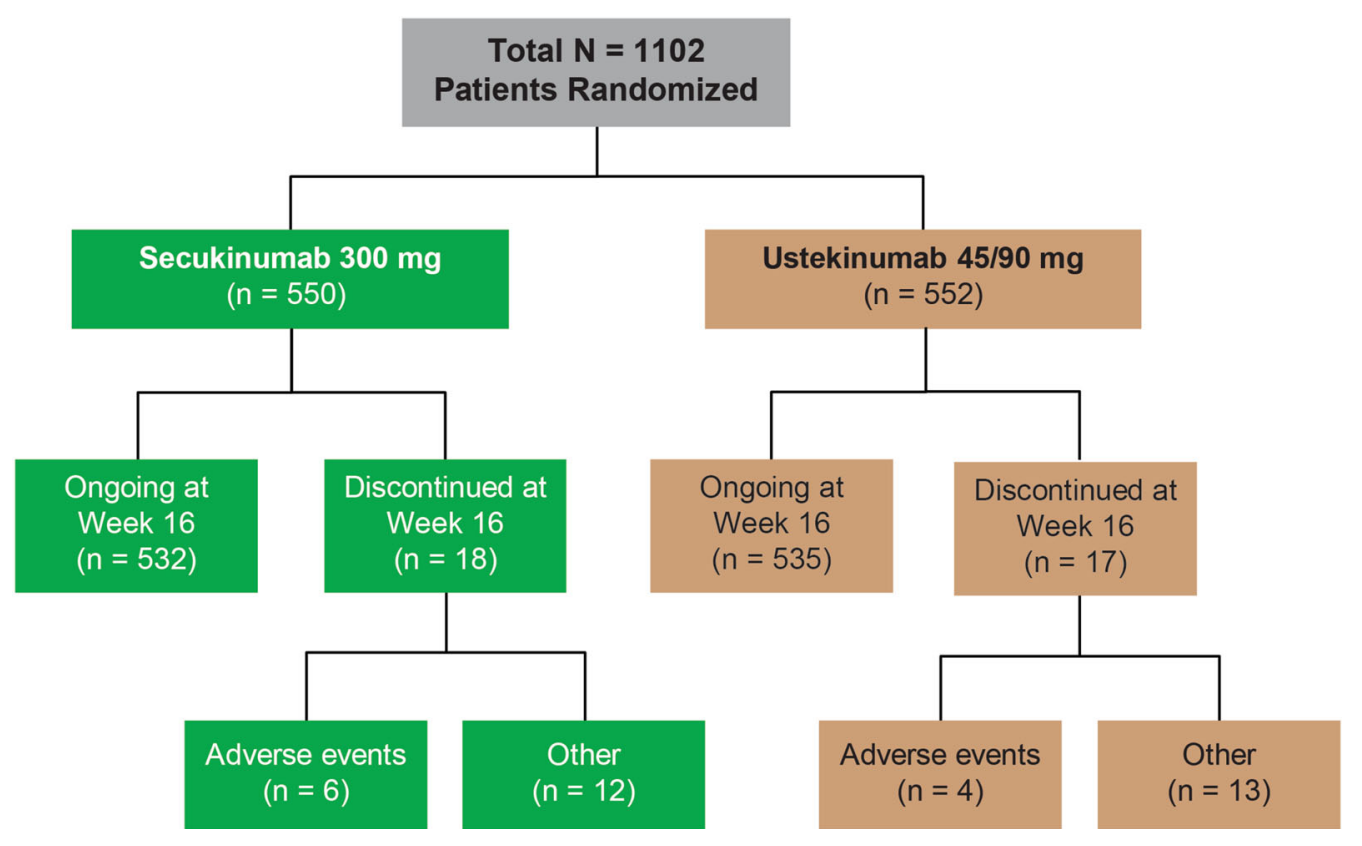

Fig. 2 Patient disposition

Table 1 Patient demographic and baseline disease characteristics

\begin{tabular}{lll}
\hline Characteristics & $\begin{array}{l}\text { Secukinumab 300 mg } \\
(\boldsymbol{n}=\mathbf{5 5 0})\end{array}$ & $\begin{array}{l}\text { Ustekinumab 45/90 mg } \\
(\boldsymbol{n}=\mathbf{5 5 2})\end{array}$ \\
\hline Age, years (mean \pm SD) & $45.4 \pm 14.1$ & $45.3 \pm 14.2$ \\
Gender-male, $n(\%)$ & $356(64.7)$ & $376(68.1)$ \\
Race-Caucasian, $n(\%)$ & $414(75.3)$ & $410(74.3)$ \\
Body weight (mean \pm SD) & $91.0 \pm 24.9$ & $93.0 \pm 24.9$ \\
$>100 \mathrm{~kg}, n(\%)$ & $189(34.4)$ & $188(34.1)$ \\
PASI (mean \pm SD) & $20.8 \pm 9.0$ & $21.3 \pm 9.2$ \\
PASI $>20, n(\%)$ & $210(38.2)$ & $226(40.9)$ \\
BSA affected, \% (mean \pm SD) & $29.2 \pm 17.9$ & $29.5 \pm 17.7$ \\
IGA mod 2011-severe disease, $n$ (\%) & $209(38.0)$ & $239(43.3)$ \\
Mean time since first diagnosis of plaque-type psoriasis, years & $16.8 \pm 11.9$ & $17.3 \pm 13.3$ \\
$\quad($ mean \pm SD) & & $130(23.6)$ \\
Previous exposure to biologic psoriasis therapy-yes, $n(\%)$ & $110(20.0)$ & \\
\hline
\end{tabular}

BSA body surface area, IGA mod 2011 Investigator's Global Assessment 2011 modification, PASI Psoriasis Area and Severity Index, $S D$ standard deviation

responses at Week $12(66.5 \%$ vs. $47.9 \%$; $p<0.0001)$ and for the proportion of patients that achieved IGA mod $20110 / 1$ responses at
Week 12 (72.3\% vs. 55.4\%; $p<0.0001)$ (Fig. 3). Indeed, PASI 90 responses were greater with secukinumab compared to ustekinumab from as 

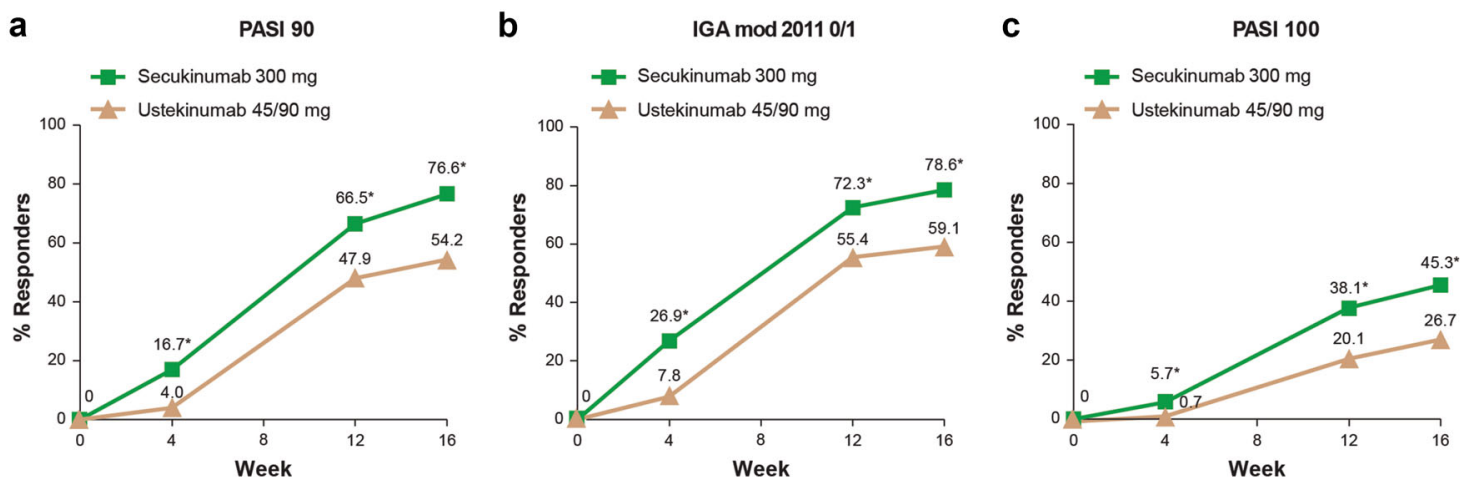

Fig. 3 PASI 90 (a), IGA mod $20110 / 1$ (b), and PASI 100 (c) responses out to Week 16. Missing values handled by multiple imputation. IGA mod $20110 / 1$ Investigator's Global Assessment, 2011 modification, clear (0) or almost

early as Week $4 \quad(16.7 \%$ vs. $4.0 \%$; $p<0.0001)$, and out to Week $16(76.6 \%$ vs. $54.2 \% ; p<0.0001)$. Similarly, IGA mod 2011 $0 / 1$ findings were greater with secukinumab at Week $4(26.9 \%$ vs. $7.8 \% ; p<0.0001)$ and at Week 16 (78.6\% vs. 59.1\%; $p<0.0001)$. Clear skin responses (PASI 100) were also greater among secukinumab treated patients compared to ustekinumab at every time point from Week 4 out to Week 16 (Fig. 3).

All key secondary objectives assessing the superiority of secukinumab to ustekinumab were also met in the hierarchical testing strategy (Table 2). clear (1) score, PASI 90 Psoriasis Area and Severity Index 90\% improvement vs. Baseline, PASI 100 Psoriasis Area and Severity Index 100\% improvement vs Baseline. ${ }^{*} p<$ 0.0001

\section{Quality of Life}

The proportion of patients with a DLQI 0/1 response was greater with secukinumab compared to ustekinumab at Week $4(33.9 \%$ vs. $18.0 \% ; p<0.0001)$, at Week $12(64.0 \%$ vs. $51.7 \% ; p<0.0001)$, and at Week $16(68.4 \%$ vs. 55.9\%; $p<0.0001$ ) (Fig. 4).

\section{Safety}

Treatment-emergent adverse events (AEs) reported up to week 16 for both the secukinumab and ustekinumab treatment groups are presented in Table 3. The total number of reported AEs was comparable between the

Table 2 Hierarchical efficacy analysis of key secondary objectives (\% responders)

\begin{tabular}{|c|c|c|c|}
\hline Parameters & Secukinumab $300 \mathrm{mg}(n=550)$ & Ustekinumab $45 / 90 \mathrm{mg}(n=552)$ & $p$ value \\
\hline PASI 75 at Week 12 & $88.0 \%$ & $74.2 \%$ & $<0.0001$ \\
\hline PASI 75 at Week 4 & $40.2 \%$ & $16.3 \%$ & $<0.0001$ \\
\hline PASI 90 at Week 16 & $76.6 \%$ & $54.2 \%$ & $<0.0001$ \\
\hline PASI 100 at Week 16 & $45.3 \%$ & $26.7 \%$ & $<0.0001$ \\
\hline IGA mod 2011 0/1 at Week 16 & $78.6 \%$ & $59.1 \%$ & $<0.0001$ \\
\hline PASI 100 at Week 12 & $38.1 \%$ & $20.1 \%$ & $<0.0001$ \\
\hline PASI 75 at Week 16 & $91.7 \%$ & $79.8 \%$ & $<0.0001$ \\
\hline
\end{tabular}

IGA mod 2011 0/1 investigator's global assessment 2011 modification clear (0) or almost clear (1), PASI psoriasis area and severity index 


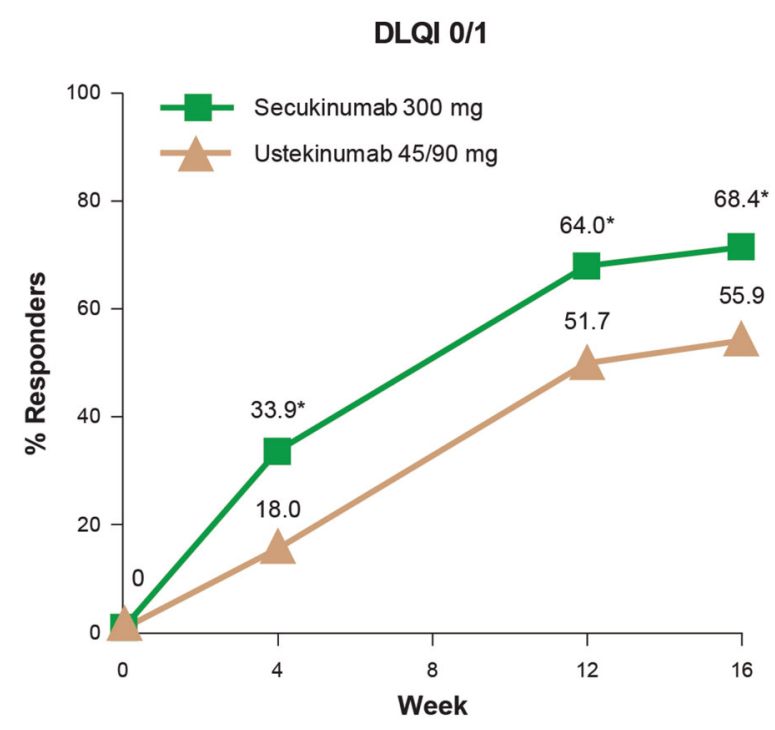

Fig. 4 DLQI 0/1 response out to Week 16. Missing values handled by last observation carried forward. DLQI $0 / 1$ Dermatology Life Quality Index 0/1 (representing no impact of skin disease on patients' quality of life). ${ }^{*} p<0.0001$

secukinumab group (47.5\%) and the ustekinumab group (46.4\%). There were two deaths, one due to acute intoxication by cocaine and another due to sudden cardiac death (patient had a history of hypertension and atherosclerosis). The incidence of non-fatal serious AEs (SAEs) was low for both groups $(2.5 \%$ for secukinumab and $1.6 \%$ for ustekinumab). AEs in the system organ class of "infections and infestations" were reported most often $(22.2 \%$ for secukinumab and $21.2 \%$ for ustekinumab); however, most events were non-serious, manageable, and did not lead to study drug discontinuation. To maintain blinding until after the final database lock at Week 52, the distributions of rare AEs for both study treatments are not presented.

\section{DISCUSSION}

Psoriasis is a complex disease associated with a notable patient burden and comorbidity. Studies comparing the effectiveness of therapies in moderate to severe plaque psoriasis are important to facilitate an informed choice of treatment for patients. This 16-week analysis of the
Table 3 Treatment-emergent adverse events to Week 16

\begin{tabular}{lll}
\hline $\begin{array}{l}\text { Treatment } \\
\text { emergent AEs }\end{array}$ & $\begin{array}{l}\text { Secukinumab } \\
\mathbf{3 0 0} \mathbf{~ m g} \\
(\boldsymbol{n}=\mathbf{5 5 0})\end{array}$ & $\begin{array}{l}\text { Ustekinumab } \\
\mathbf{4 5} / \mathbf{9 0} \mathbf{~ m g} \\
(\boldsymbol{n}=\mathbf{5 5 2})\end{array}$ \\
\hline $\begin{array}{l}\text { Duration of exposure } \\
\text { (subject years) }\end{array}$ & 170.8 & 171.1 \\
All AEs & $261(47.5)$ & $256(46.4)$ \\
All non-fatal SAEs & $14(2.5)$ & $9(1.6)$ \\
$\begin{array}{l}\text { Discontinued study } \\
\text { treatment due to }\end{array}$ & $11(2.0)$ & $7(1.3)$ \\
any AE & & \\
Most frequent AEs ${ }^{\mathrm{a}}$ & & \\
Nasopharyngitis & $25(4.5)$ & $25(4.5)$ \\
URTI & $25(4.5)$ & $33(6.0)$ \\
Diarrhea & $17(3.1)$ & $12(2.2)$ \\
Headache & $16(2.9)$ & $15(2.7)$ \\
Sinusitis & $11(2.0)$ & $7(1.3)$ \\
Infections and & $122(22.2)$ & $117(21.2)$ \\
infestations & & \\
\hline
\end{tabular}

Data are $n(\%)$ unless otherwise stated

$A E$ adverse event, $S A E$ serious adverse event, URTI upper respiratory tract infection

${ }^{a}$ By preferred term and occurring at an incidence of $\geq 2 \%$ in either treatment arm. AEs are listed in decreasing order of frequency in the secukinumab arm

CLARITY study confirmed the superiority of secukinumab compared to ustekinumab in clearing skin, and achieving a greater quality of life improvement, in patients with moderate to severe plaque psoriasis.

Ustekinumab is a fully human monoclonal anti-IL-12/23 antibody, which has proved to be a safe and efficacious treatment for moderate to severe plaque psoriasis. PASI 90 response rates of approximately $42 \%$ were reported with ustekinumab (combined doses) in pivotal studies (PHOENIX 1, PHOENIX 2, and ACCEPT) after 12 weeks of treatment $[1,2,7]$. Secukinumab is a fully human monoclonal anti-IL-17A antibody, which has shown long-lasting efficacy and safety for a variety of psoriasis manifestations, including psoriatic arthritis and psoriasis 
localized to the nails, scalp, palms, and soles [5, 8-12]. In the double-blinded CLEAR study, secukinumab (79.0\%) was found to be superior to ustekinumab $(57.6 \%)$ in treating patients with moderate to severe plaque psoriasis, as assessed by PASI 90 response at Week 16 $(p<0.0001)$ [5]. In the present CLARITY study, it was again found that secukinumab had a superior PASI 90 response to ustekinumab, both at Week 12 (66.5\% vs. $47.9 \% ; p<0.0001)$ and at Week 16 (76.6\% vs. 54.2\%; $p<0.0001)$. Secukinumab also demonstrated an earlier onset of response than ustekinumab; $40.2 \%$ of secukinumab-treated patients were PASI 75 responders as early as Week 4 compared to $16.3 \%$ $(p<0.0001)$ of ustekinumab-treated patients.

In an era of more efficacious biologic treatments, a state of clear or almost clear skin is considered an achievable therapeutic target for psoriasis patients $[13,14]$. In our study, a greater proportion of patients achieved clear or almost clear skin (IGA mod 2011 0/1) after 12 weeks of secukinumab treatment in comparison to ustekinumab treatment $(72.3 \%$ vs. $55.4 \%$; $p<0.0001$ ). Similarly, IGA mod $20110 / 1$ rates were higher for those receiving secukinumab in comparison to ustekinumab at Week $16(78.6 \%$ vs. $59.1 \% ; p<0.0001)$. With secukinumab demonstrating superiority to ustekinumab for both PASI 90 and IGA mod 2011 0/1 responses at Week 12, both co-primary endpoints of the study were met.

Patients with psoriasis experience a significant impairment to their quality of life [15]. Thus, it is recommended to include quality of life outcome measures as therapeutic targets [13]. The proportion of patients reporting no impact of skin disease on their quality of life (DLQI 0/1 response) was examined in this study. We found that patients treated with secukinumab had superior improvements in DLQI $0 / 1$ to ustekinumab at Weeks $12(64.0 \%$ vs. $51.7 \%$, respectively) and $16(68.4 \%$ vs. $55.9 \%)$. These findings are similar to those reported in the CLEAR study, where the proportion of DLQI 0/1 responders was also greater at Week 16 with secukinumab (71.9\%) compared to ustekinumab (57.4\%) [5].

Similar to previous secukinumab clinical trials, the safety profile of secukinumab remained favorable with no new safety signals identified to Week 16. Complete safety data from the 52-week CLARITY trial will be presented later.

This is the second head-to-head trial demonstrating the superior efficacy of secukinumab compared to ustekinumab in treating patients with moderate to severe psoriasis. The CLARITY study included a larger patient population $(N=1102$ vs. $N=676)$ and a greater proportion of US patients $(64.2 \%$ vs. $12.6 \%)$ than the CLEAR study.

A potential limitation of the CLARITY study is the absence of a placebo arm. Since both secukinumab and ustekinumab have previously demonstrated superior efficacy compared with placebo in phase 3 trials, the inclusion of a placebo arm here was considered unethical $[1,8]$. In addition, while patient-reported DLQI was examined in the present study, other patient reported outcomes (such as relief of symptoms) were not. Previously, in the CLEAR study, secukinumab was found to be superior to ustekinumab at reducing psoriasis-related pain, itching, and scaling through 52 weeks of treatment [6].

\section{CONCLUSIONS}

The results of this study confirm the superior efficacy of secukinumab over ustekinumab, with a rapid onset from Week 4, in treating patients with moderate to severe psoriasis.

\section{ACKNOWLEDGEMENTS}

The authors thank the patients and investigators who participated in the study.

Funding. This investigation was sponsored by Novartis Pharma AG, Basel, Switzerland. Novartis Pharma AG also funded the journal article processing charges. All authors had full access to all of the data in this study and take complete responsibility for the integrity of the data and accuracy of the data analysis.

Medical writing support. The authors thank Brendan Marshall, PhD of Novartis Ireland Ltd. for providing medical writing support which 
was funded by Novartis Pharma AG, Switzerland in accordance with Good Publication Practice (GPP3) guidelines (http://www.ismpp.org/ gpp3).

Authorship. All named authors meet the International Committee of Medical Journal Editors (ICMJE) criteria for authorship for this article, take responsibility for the integrity of the work as a whole, and have given their approval for this version to be published.

Disclosures. Jerry Bagel is an investigator and/or consultant and/or speaker for AbbVie, Amgen, Boehringer-Ingelheim, Janssen, Leo, Novartis, Celgene, Eli Lilly, Sun, and Valiant. Manmath Patekar is an employee of Novartis Pharma AG, Basel, Switzerland. Ana de Vera is an employee of Novartis Pharma AG, Basel, Switzerland. Sophie Hugot is an employee of Novartis Pharma AG, Basel, Switzerland. Isabelle Gilloteau is an employee of Novartis Pharma AG, Basel, Switzerland. Elisa Muscianisi is an employee of Novartis Pharmaceuticals Corporation, East Hanover, NJ, USA. Kuan Sheng is an employee of Novartis Pharmaceuticals Corporation, East Hanover, NJ, USA. Summer Xia is an employee of Beijing Novartis Pharma Co. Ltd, Shanghai, China. Andrew Blauvelt has served as a scientific consultant and clinical study investigator for AbbVie, Aclaris, Akros, Allergan, Almirall, Amgen, Boehringer Ingelheim, Celgene, Dermavant, Dermira, Eli Lilly and Company, Galderma, Genentech/Roche, GlaxoSmithKline, Janssen, Leo, Meiji, Merck Sharp \& Dohme, Novartis, Pfizer, Purdue Pharma, Regeneron, Revance, Sandoz, Sanofi Genzyme, Sienna Pharmaceuticals, Sun Pharma, UCB, Valeant, and Vidac and as a paid speaker for Janssen, Regeneron, and Sanofi Genzyme. Mark Lebwohl is an employee of Mount Sinai which receives research funds from AbbVie, Boehringer Ingelheim, Celgene, Eli Lilly, Incyte, Janssen/Johnson \& Johnson, Leo Pharmaceuticals, Medimmune/Astra Zeneca, Novartis, Pfizer, Sciderm, UCB, Valeant, and Vidac. Mark Lebwohl is also a consultant for Allergan, Aqua, Boehringer-Ingelheim, LEO Pharma, Menlo, and Promius. John Nia and Peter W. Hashim have nothing to disclose.
Compliance with Ethics Guidelines. All procedures performed in studies involving human participants were in accordance with the ethical standards of the institutional and/or national research committee and with the 1964 Helsinki declaration and its later amendments or comparable ethical standards. Informed consent was obtained from all individual participants included in the study.

Data Availability. The datasets generated during and/or analyzed during the current study are not publicly available to prevent unblinding of treatment groups in the ongoing CLARITY trial.

Open Access. This article is distributed under the terms of the Creative Commons Attribution-NonCommercial 4.0 International License (http://creativecommons.org/licenses/ by-nc/4.0/), which permits any noncommercial use, distribution, and reproduction in any medium, provided you give appropriate credit to the original author(s) and the source, provide a link to the Creative Commons license, and indicate if changes were made.

\section{REFERENCES}

1. Leonardi CL, Kimball AB, Papp KA, et al. Efficacy and safety of ustekinumab, a human interleukin$12 / 23$ monoclonal antibody, in patients with psoriasis: 76-week results from a randomised, doubleblind, placebo-controlled trial (PHOENIX 1). Lancet. 2008;371(9625):1665-74.

2. Papp KA, Langley RG, Lebwohl M, et al. Efficacy and safety of ustekinumab, a human interleukin-12/23 monoclonal antibody, in patients with psoriasis: 52-week results from a randomised, double-blind, placebo-controlled trial (PHOENIX 2). Lancet. 2008;371(9625):1675-84.

3. Zeichner JA, Armstrong A. The role of IL-17 in the pathogenesis and treatment of psoriasis. J Clin Aesthet Dermatol. 2016;9(6 Suppl 1):S3-6.

4. Blauvelt A, Chiricozzi A. The immunologic role of IL-17 in psoriasis and psoriatic arthritis pathogenesis. Clin Rev Allergy Immunol. 2018. https://doi. org/10.1007/s12016-018-8702-3. 
5. Thaci D, Blauvelt A, Reich K, et al. Secukinumab is superior to ustekinumab in clearing skin of subjects with moderate to severe plaque psoriasis: CLEAR, a randomized controlled trial. J Am Acad Dermatol. 2015;73(3):400-9.

6. Blauvelt A, Reich K, Tsai TF, et al. Secukinumab is superior to ustekinumab in clearing skin of subjects with moderate-to-severe plaque psoriasis up to 1 year: results from the CLEAR study. J Am Acad Dermatol. 2017;76(1):60-9.

7. Griffiths CE, Strober BE, van de Kerkhof P, et al. Comparison of ustekinumab and etanercept for moderate-to-severe psoriasis. New Engl J Med. 2010;362(2):118-28.

8. Langley RG, Elewski BE, Lebwohl M, et al. Secukinumab in plaque psoriasis-results of two phase 3 trials. New Engl J Med. 2014;371(4):326-38.

9. McInnes IB, Mease PJ, Kirkham B, et al. Secukinumab, a human anti-interleukin-17A monoclonal antibody, in patients with psoriatic arthritis (FUTURE 2): a randomised, double-blind, placebo-controlled, phase 3 trial. Lancet. 2015;386(9999):1137-46.

10. Baeten D, Sieper J, Braun J, et al. Secukinumab, an interleukin-17A inhibitor, in ankylosing spondylitis. New Engl J Med. 2015;373(26):2534-48.
11. European Medicines Agency. Summary of product characteristics (Secukinumab). http://www.ema. europa.eu/docs/en_GB/document_library/EPAR_-_ Product_Information/human/003729/

WC500183129.pdf. Accessed May 17, 2018.

12. Novartis US. Summary of prescribing information (Secukinumab). https://www.pharma.us.novartis. com/sites/www.pharma.us.novartis.com/files/ cosentyx.pdf. Accessed May 17, 2018.

13. Gladman DD, Poulin Y, Adams K, et al. Treating psoriasis and psoriatic arthritis: position paper on applying the treat-to-target concept to Canadian daily practice. J Rheum. 2017;44(4):519-34.

14. Armstrong AW, Siegel MP, Bagel J, et al. From the medical board of the National Psoriasis Foundation: treatment targets for plaque psoriasis. J Am Acad Dermatol. 2017;76(2):290-8.

15. Armstrong AW, Schupp C, Wu J, Bebo B. Quality of life and work productivity impairment among psoriasis patients: findings from the National Psoriasis Foundation survey data 2003-2011. PLoS One. 2012;7(12):e52935. 